\title{
Chemical synthesis of C6-tetrazole D-mannose building blocks and access to a bioisostere of mannuronic acid 1-phosphate
}

\author{
Eleni Dimitriou and Gavin J. Miller ${ }^{\star}$
}

\author{
Letter \\ Address: \\ Lennard-Jones Laboratory, School of Chemical and Physical \\ Sciences, Keele University, Keele, Staffordshire, ST5 5BG, U. K. \\ Email: \\ Gavin J. Miller* - g.j.miller@keele.ac.uk \\ * Corresponding author \\ Keywords: \\ alginate; glycosyl 1-phosphate; non-native monosaccharide; tetrazole; \\ uronate
}

\author{
Beilstein J. Org. Chem. 2021, 17, 1527-1532. \\ https://doi.org/10.3762/bjoc. 17.110 \\ Received: 20 March 2021 \\ Accepted: 24 June 2021 \\ Published: 05 July 2021 \\ Associate Editor: T. J. J. Müller \\ (C) 2021 Dimitriou and Miller; licensee Beilstein-Institut. \\ License and terms: see end of document.
}

\begin{abstract}
Alginate is a biocompatible and industrially relevant polysaccharide that derives many of its important properties from the charged carboxylate groups within its polyuronic acid backbone. The design and inclusion of isosteric replacements for these carboxylates would underpin provision of new oligo-/polysaccharide materials with alternate physicochemical properties. Presented herein is our synthesis of mannuronic acid building blocks, appropriately modified at the carboxylate C6 position with a bioisosteric tetrazole. Thioglycosides containing a protected C6-tetrazole are accessed from a C6-nitrile, through dipolar cycloaddition using $\mathrm{NaN}_{3}$ with $n$ - $\mathrm{Bu}_{2} \mathrm{SnO}$. We also demonstrate access to orthogonally C4-protected donors, suitable for iterative oligosaccharide synthesis. The development of these building blocks is showcased to access anomeric 3-aminopropyl- and 1-phosphate free sugars containing this non-native motif.
\end{abstract}

\section{Introduction}

Alginate is an important, industrially relevant polysaccharide chemically composed of $\beta$-1,4-linked D-mannuronic acid (M) and $\alpha$-L-guluronic acid (G) monosaccharide building blocks (Figure 1a). Because of its biocompatibility, alginate has several commercial industrial applications; for example, it is widely used as a gelling agent [1-5]. Detailed consideration of the alginate sub-structure indicates non-uniform proportions of $\mathbf{M}$ and G units (and their homo- or heteropolymeric block-groupings) which, alongside acetylation of $\mathbf{M}$ residues, presents a structurally heterogeneous polysaccharide. Ultimately, this hetero-

geneity contributes to the physicochemical properties of the polysaccharide system, presenting an opportunity to explore modifying the chemical structure of alginate, with a view to both understanding and imparting changes upon its structure-tofunction relationships.

To this end, synthetic chemistry strategies (both solution and solid phase) have demonstrated exciting capabilities for access to native alginate oligosaccharides in recent years [6-10]. As part of a program to access non-native alginate oligosaccharide 
a) alginate structure

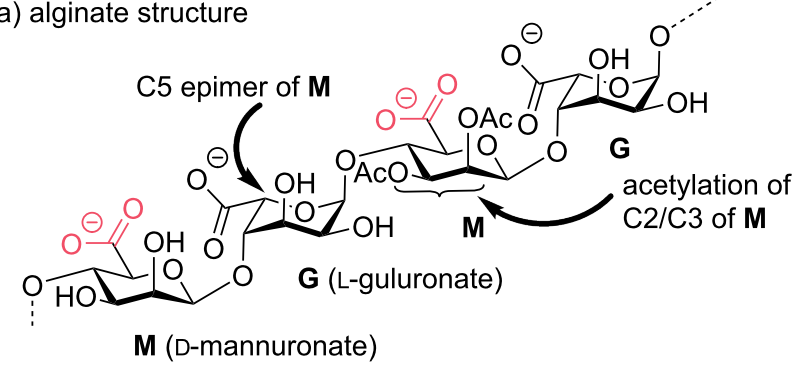

b) prospects for bioisosteric replacement of C5-mannuronic acid

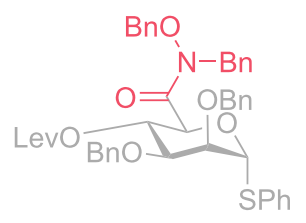

previously reported hydroxamate building blocks

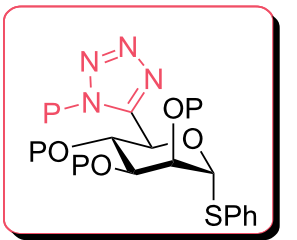

this work: C6-tetrazole D-manno thioglycoside donors

Figure 1: a) Chemical structure of alginate showing constituent $\mathbf{M}$ and $\mathbf{G}$ residues and $\mathrm{C} 2 / \mathrm{C} 3$ acetylation for one $\mathbf{M}$ residue. b) Introduction of bioisosteric carboxylate groups at C6 within a D-manno thioglycoside donor, $\mathrm{P}=$ appropriate protecting group.

sequences, we targeted a synthetic approach to provide structurally defined building blocks containing bioisosteres of D-mannuronic acid. Building on our recently reported synthesis and glycosylation capability of hydroxamate-modified D-mannuronate building blocks [11], we now demonstrate the synthesis of a second carboxylate C6-bioisostere, tetrazole (Figure 1b).

As an established bioisostere for a carboxylic acid, tetrazole has found significant application within medicinal chemistry [12]. The aromatic tetrazole ring is considered a non-classical bioisostere, differing in size and number of atoms to the carboxylic acid. The functional group has a similar $\mathrm{p} K_{\mathrm{a}}$ to a carboxylate yet provides enhanced hydrogen bonding capability and alternative prospects for permeability due to a larger hydrophobic region enabling improved lipophilic contacts. These alternative properties and a prospect for their inclusion within new alginate fragments led us to explore the synthesis of a D-manno C6-tetrazole thioglycoside donor and examine subsequent installation of $\mathrm{C} 1$ phosphate and anomeric linker groups.

\section{Results and Discussion}

An initial route towards a protected C6-tetrazole building block started from known mannuronic acid thioglycoside $\mathbf{1}$ (Scheme 1) [13], from which we recently effected coupling to

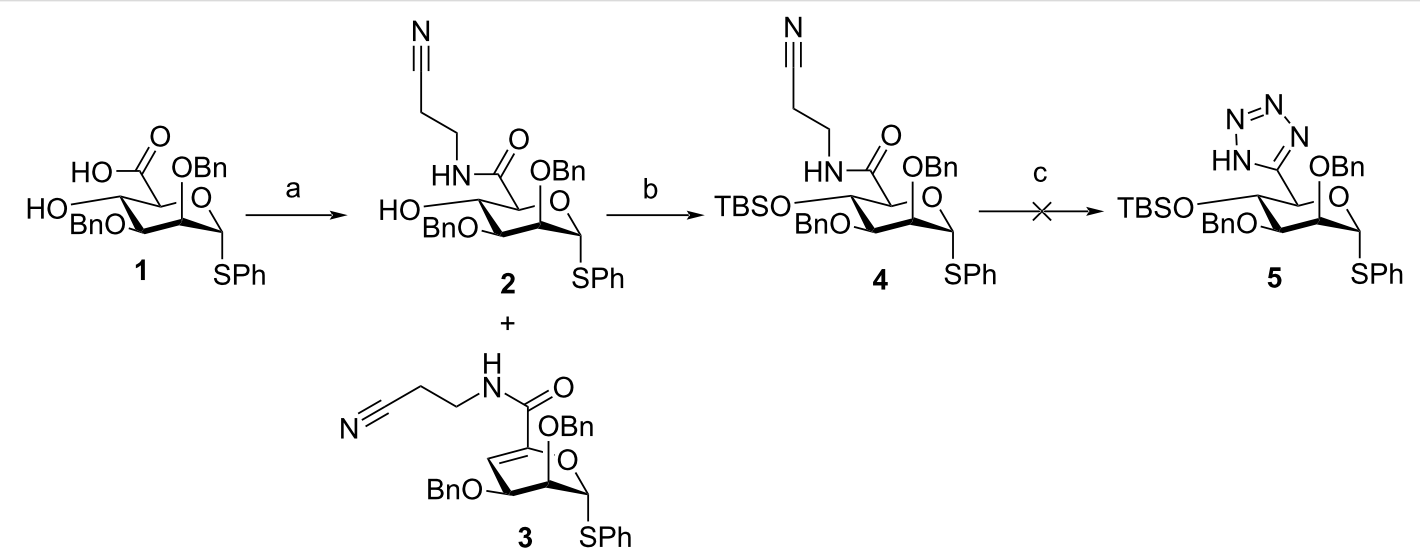

Scheme 1: a) $\mathrm{H}_{2} \mathrm{~N}\left(\mathrm{CH}_{2}\right)_{2} \mathrm{CN}$, PyBOP, DIPEA, $\mathrm{CH}_{2} \mathrm{Cl}_{2}, 0{ }^{\circ} \mathrm{C}, 40 \mathrm{~min}, 47 \%$ (+44\% 3); b) TBSOTf, imidazole, DMAP, DMF, $24 \mathrm{~h}, 80 \%$; c) PPh 3 , DIAD, $\mathrm{TMSN}_{3}, \mathrm{MeCN}, 80^{\circ} \mathrm{C}, 48 \mathrm{~h}$. 
yield a protected C6 hydroxamate [11]. Accordingly, 1 was stirred with PyBOP and DIPEA in $\mathrm{CH}_{2} \mathrm{Cl}_{2}$ for 5 minutes, before 3 -aminopropionitrile was added. After stirring for 1.5 hours at room temperature an undesired $\mathrm{C} 4-\mathrm{C} 5$ elimination material 3 was isolated as the major product in $35 \%$ yield, with only a trace amount of the desired $\mathbf{2}$ formed (7\% yield). The ability of 3 -aminopropionitrile to act as a base and trigger this elimination was comparable to results we observed using $\mathrm{N}, \mathrm{O}$-dibenzylhydroxylamine as the coupling partner [11]. In the latter instance we were able to modify the nucleophile component to $O$-benzylhydroxylamine and supress unwanted elimination. Unable to do this here, we instead reduced the reaction temperature to $0{ }^{\circ} \mathrm{C}$, maintaining this for 40 minutes. Pleasingly, the yield and product distribution were improved, affording separable amounts of 2 and 3 in $47 \%$ and $44 \%$ yields, respectively.

Subsequent silyl protection of the C4-hydroxy group in $\mathbf{2}$ was completed using TBSOTf, furnishing $\mathbf{4}$ in $80 \%$ yield. Attempts to next convert $\mathbf{4}$ to $\mathbf{5}$ (via an $N$-cyanoethyl-protected tetrazole) using $\mathrm{PPh}_{3}$, DIAD and TMSN 3 were unsuccessful, despite repeated attempts [14]. TLC and NMR analysis consistently indicated no conversion of $\mathbf{4}$, even after stirring at $80{ }^{\circ} \mathrm{C}$ in $\mathrm{MeCN}$ for 48 hours. We therefore proposed an alternative route to $\mathbf{5}$, directly from reaction of a $\mathrm{C} 6$ nitrile with $\mathrm{NaN}_{3}$, obviating the need for intermediate cyanoacetamide formation (Scheme 2).

This second route commenced with a three-step protecting group manipulation of primary alcohol 6, delivering 7 in $63 \%$ yield over three steps (Scheme 2). Alcohol 7 was then subjected to Parikh-Doering oxidation to deliver a crude aldehyde in
$98 \%$ yield, from which oxime $\mathbf{8}$ was subsequently formed in $80 \%$ yield as a $6.7: 1$ mixture of $\mathrm{C}=\mathrm{N}$ isomers. Dehydration of $\mathbf{8}$ using $\mathrm{POCl}_{3}$ gave 9 in a low $40 \%$ yield, alongside $10(26 \%$ yield). Formation of $\mathbf{1 0}$ was attributed to the acidic reaction conditions concomitantly effecting TBS removal. However, further amounts of 9 could be accessed through reprotection at C4 with TBSOTf in excellent yield (87\%). C6-nitrile 9 was then successfully converted into C6-tetrazole 5 in 51\% yield using $\mathrm{TMSN}_{3}$ and a catalytic amount of $\mathrm{Bu}_{2} \mathrm{SnO}$ [15]. This method was recently utilised successfully by Bräse and colleagues for D-gluco-configured C6-tetrazoles in their synthesis of modified hyaluronic acid fragments [16]. ${ }^{13} \mathrm{C}$ NMR of 5 confirmed the presence of a new quaternary carbon (tetrazole $\mathrm{C}_{\mathrm{q}}$, $\delta_{\mathrm{C}}=155.8 \mathrm{ppm}$ ) alongside disappearance of the C6-nitrile $\left(\delta_{\mathrm{C}}=117.0 \mathrm{ppm}\right)$. Furthermore, ${ }^{1} \mathrm{H}$ NMR analysis indicated the common $\mathrm{H} 5$ doublet was further downfield $\left(\delta_{\mathrm{H}}=5.64 \mathrm{ppm}\right)$, compared to data observed previously for mannuronate ester $\left(\delta_{\mathrm{H}}=4.54 \mathrm{ppm}\right)$ and hydroxamate $\left(\delta_{\mathrm{H}}=4.56 \mathrm{ppm}\right)$ motifs [11]. Finally, the coupling constant calculated for $\mathrm{H} 5$ $\left({ }^{3} J_{\mathrm{H} 5-\mathrm{H} 4}=8.9 \mathrm{~Hz}\right)$, indicated a solution-phase ${ }^{4} C_{1}$ pyranose conformation for newly formed 5 .

To explore improving the efficiency of the latter synthetic steps towards 5, an alternative, one-pot three-component procedure $\left(\mathrm{H}_{2} \mathrm{~N}-\mathrm{OH}, \mathrm{NaN}_{3}\right.$ and catalytic $\left.\left[\left(\mathrm{NH}_{4}\right)_{4} \mathrm{Ce}\left(\mathrm{SO}_{4}\right)_{4}\right]\right)$ was attempted from the crude C6-aldehyde [17]. TLC analysis indicated C6-nitrile formation was evident after $36 \mathrm{~h}$, however, the desired C6-tetrazole 5 was not observed. Repeated attempts were unable to indicate progress beyond mixtures of $\mathbf{8}$ and $\mathbf{9}$ in $35 \%$ and $14 \%$ yields and the procedure was abandoned, instead reverting to the successful route developed in Scheme 2.

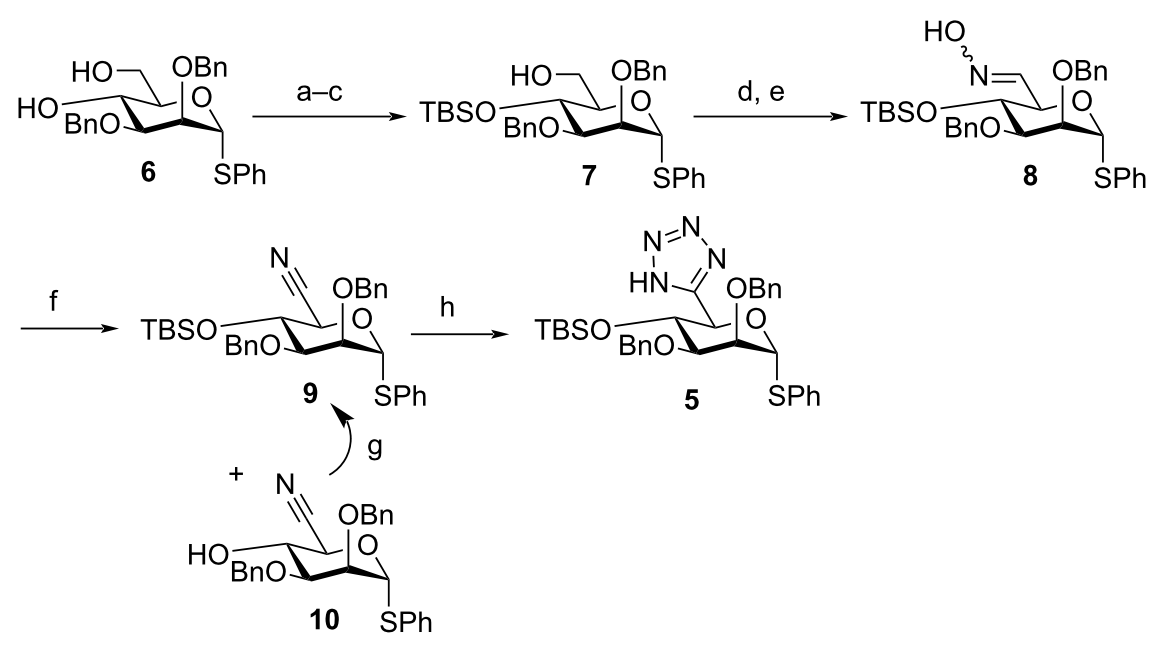

Scheme 2: a) BzCl, DMAP, pyridine, $\mathrm{CH}_{2} \mathrm{Cl}_{2}$, rt, $24 \mathrm{~h}, 90 \%$; b) TBSOTf, imidazole, DMAP, DMF, $40{ }^{\circ} \mathrm{C}, 24 \mathrm{~h}, 78 \%$; c) $\mathrm{Na}(\mathrm{s}), \mathrm{MeOH}, \mathrm{THF}, 16 \mathrm{~h}, 90 \%$; d) DMSO, $\mathrm{SO}_{3}$.pyridine, $\mathrm{Et}_{3} \mathrm{~N}$, rt, $1 \mathrm{~h}, 98 \%$; e) $\mathrm{H}_{2} \mathrm{NOH} \cdot \mathrm{HCl}$, THF, $\mathrm{H}_{2} \mathrm{O}, \mathrm{Na}_{2} \mathrm{CO}_{3}, 24 \mathrm{~h}, 80 \%$; f) $\mathrm{POCl}_{3}, \mathrm{MeCN}^{\circ} 65^{\circ} \mathrm{C}, 40 \%$; g) $\mathrm{TBSOTf}$, imidazole, DMAP, DMF, rt, $24 \mathrm{~h}, 87 \%$; h) $\mathrm{TMSN}_{3}, \mathrm{Bu}_{2} \mathrm{SnO}$, toluene, $120{ }^{\circ} \mathrm{C}, 51 \%$. 
The final step towards the synthesis of a fully protected C6-tetrazole glycosyl donor required tetrazole nitrogen protection (Scheme 3). A first attempt here involved the reaction of $\mathbf{5}$ with $\mathrm{PMBCl}$ in DMF, using $\mathrm{K}_{2} \mathrm{CO}_{3}$ alongside KI. Two separable regioisomers $\mathbf{1 1}$ and $\mathbf{1 2}$ were isolated in an acceptable $53 \%$ overall yield and in a ratio of $N_{1}-\mathrm{PMB} / N_{2}-\mathrm{PMB}=1.1: 1$ (Scheme 3). HMBC NMR of $\mathbf{1 1}$ and $\mathbf{1 2}$ clarified the position of the PMB group on the tetrazole ring for each compound. For 11, a correlation of tetrazole $\mathrm{C}_{\mathrm{q}}\left(\delta_{\mathrm{C}}=150.4 \mathrm{ppm}\right)$ with the benzylic protons of the PMB group $\left(\delta_{\mathrm{H}}=5.66 \mathrm{ppm}\right.$, see Supporting Information File 1, Figure S3), was observable. Similar analysis for $\mathbf{1 2}$ indicated no such correlation. In order to try and

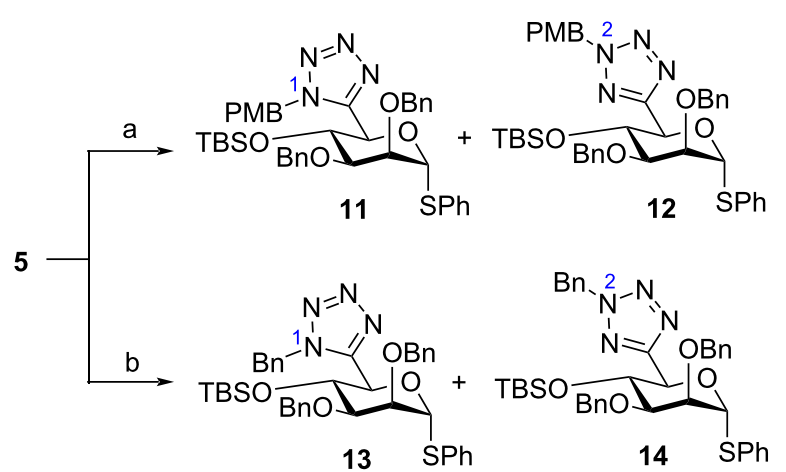

Scheme 3: a) PMBCI, $\mathrm{KI}, \mathrm{K}_{2} \mathrm{CO}_{3}, \mathrm{DMF}$, rt, $53 \%$ for 11 and 12; b) $\mathrm{BnBr}, \mathrm{DMF}, \mathrm{Et}_{3} \mathrm{~N}, \mathrm{DCM}, \mathrm{rt}, 31 \%$ for $\mathbf{1 3}$ and 14 . improve the $N_{1}$-PMB $/ N_{2}$-PMB ratio, converting 5 to a triethylammonium salt form in $94 \%$ yield was adopted [18]. Subsequent reaction with $\mathrm{PMBCl}$ gave 11 and 12, but in a largely unchanged ratio $\left(N_{1}-\mathrm{PMB} / N_{2}-\mathrm{PMB}=1: 1.1\right)$. A comparative attempt to install a benzyl protecting group using this method afforded $N_{1}$-Bn and $N_{2}$-Bn tetrazoles 13 and 14 in low yield $(31 \%)$ and again with little regiodiscrimination $\left(N_{1}-\mathrm{Bn} / N_{2}-\mathrm{Bn}=\right.$ $1: 1.2)$.

The synthesis of appropriately protected C6-tetrazole donors 11-14 was accomplished to allow for regioselective deprotection and unveil C4-acceptor capability within a broader oligosaccharide synthesis strategy. With such capability effectively demonstrated, we next explored the provision of D-manno C6-tetrazoles without an orthogonal C4-protecting group.

Accordingly, a synthesis initiating from alcohol 15 [19] enabled access to C6-nitrile 16 in three steps (Scheme 4) and an improved yield of $50 \%$ (compared to $31 \%$ in accessing 9 from 7 ). Nitrile 16 then underwent dipolar cycloaddition with $\mathrm{NaN}_{3}$, converting it to C6-tetrazole thioglycoside $\mathbf{1 7}$ in 55\% yield. This material was then protected at tetrazole nitrogen in $76 \%$ yield using $\mathrm{PMBCl}$ to give 18 and $19\left(N_{1}-\mathrm{PMB} / N_{2}-\mathrm{PMB}=\right.$ $1: 1.2)$ as separable regioisomers and their structures were confirmed by HMBC, as previously demonstrated. Removal of the need to orthogonally protect $\mathrm{C} 4$ expectedly reduced the complexity of the synthetic route and nine steps for the synthesis of
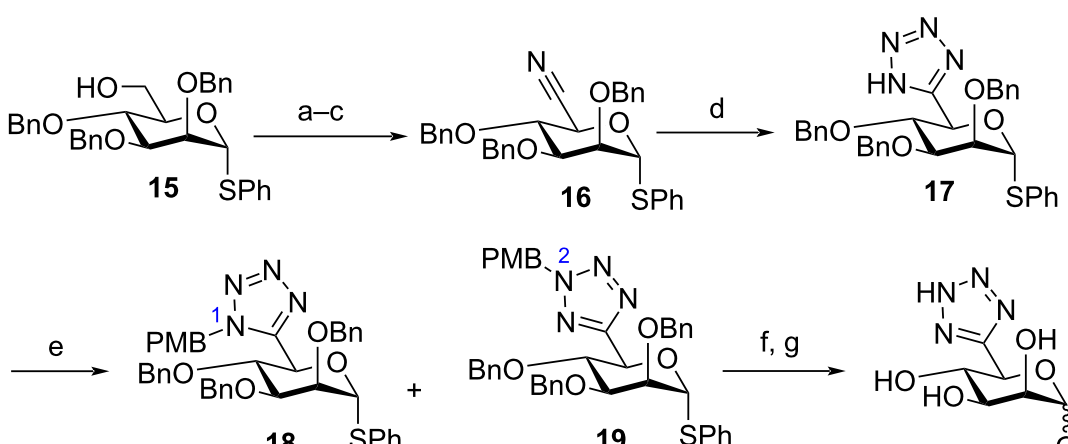

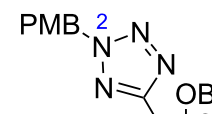
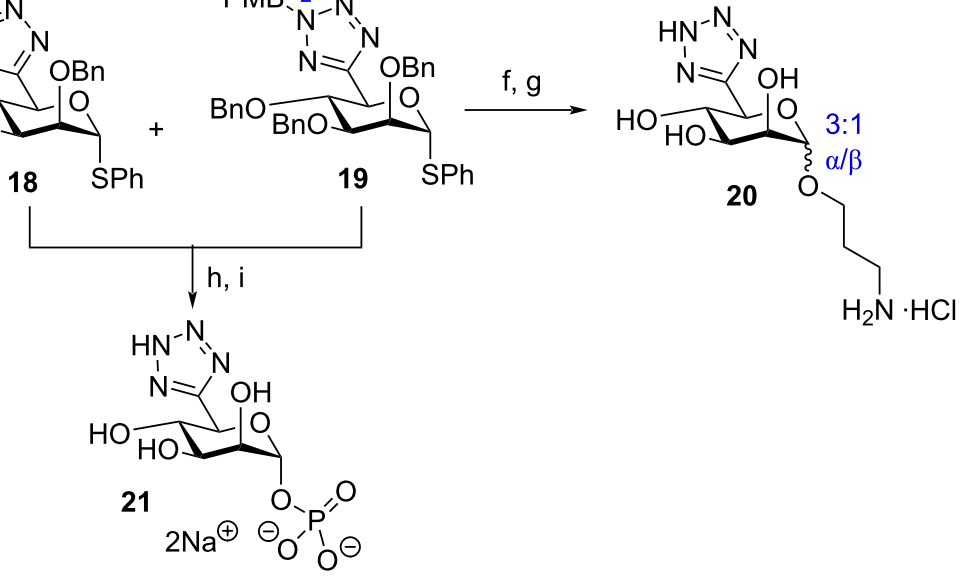

Scheme 4: a) DMSO, $\mathrm{SO}_{3}$ 'pyridine, $\mathrm{Et}_{3} \mathrm{~N}, \mathrm{rt}, 1 \mathrm{~h}, 96 \%$; b) $\mathrm{H}_{2} \mathrm{NOH} \cdot \mathrm{HCl}$, THF, $\mathrm{H}_{2} \mathrm{O}, \mathrm{Na}_{2} \mathrm{CO}_{3}, 89 \%$; c) $\mathrm{POCl}_{3}, \mathrm{MeCN}, 65{ }^{\circ} \mathrm{C}, 59 \%$; d) $\mathrm{TMSN}_{3}, \mathrm{Bu}_{2} \mathrm{SnO}_{\text {, }}$ toluene, $120^{\circ} \mathrm{C}, 55 \%$; e) PMBCl, $\mathrm{KI}, \mathrm{K}_{2} \mathrm{CO}_{3}, \mathrm{DMF}, 76 \%$ for 18 and 19; f) 3-(benzyloxycarbonylamino)-propan-1-ol, NIS, $\mathrm{AgOTf} \mathrm{CH}_{2} \mathrm{Cl}_{2},-40$ to $\left.-10{ }^{\circ} \mathrm{C}, 3 \mathrm{~h}, 34 \% ; \mathrm{g}\right) \mathrm{H}_{2}(\mathrm{~g}), \mathrm{Pd} / \mathrm{C}, \mathrm{Pd}(\mathrm{OH})_{2} / \mathrm{C}, \mathrm{HCl}$, EtOH, THF, rt, $56 \mathrm{~h}, 96 \%$; h) dibenzyl phosphate, NIS, $\mathrm{AgOTf}, \mathrm{CH}_{2} \mathrm{Cl}_{2},-30$ to $0{ }^{\circ} \mathrm{C}, 3.5 \mathrm{~h}, 72 \%$; i) $\mathrm{H}_{2}(\mathrm{~g}), \mathrm{Pd} / \mathrm{C}, \mathrm{Pd}(\mathrm{OH})_{2} / \mathrm{C}, 5 \% \mathrm{NaHCO}_{3}, \mathrm{EtOH}, \mathrm{THF}, \mathrm{rt}, 24 \mathrm{~h}, 72 \%$. 
donors of type 11/12 was reduced to five steps for $18 / 19$. Moreover, the overall yield for the route increased from 9 to $21 \%$.

To demonstrate capability for anomeric linker attachment and conversion to a biologically relevant analogue of mannuronic acid 1-phosphate, 3-aminopropyl glycoside $\mathbf{2 0}$ and glycosyl 1-phosphate 21 were synthesised (Scheme 4). The mixture 18/19 was used for glycosylation of 3-(benzyloxycarbonylamino)-1-propanol and furnished a regioisomeric and anomeric mixture in low yield (34\%, with $20 \%$ recovered starting material and $18 \%$ hydrolysed donor, $3: 1, \alpha / \beta$ ). The $\beta$-linked (minor) anomer was identified through ${ }^{1} J_{\mathrm{C}-\mathrm{H}}$ coupling constant data $(J=156 \mathrm{~Hz})$, similar to products obtained using C6-mannuronate and C6-hydroxamate donors [11]. This initial result suggests a reduced capability using C6-tetrazole donors with a primary alcohol acceptor; comparative yields for glycosylation of 3-bromopropanol using C6-hydroxamate and C6-mannuronate donors were $65-85 \%$ and exclusively $\beta$-selective [11]. Isomeric separation of this complex mixture was not completed at this stage and the material was next deprotected using hydrogenolysis to remove the benzyl groups. This furnished 20 in excellent yield $(96 \%)$ as a $3: 1 \alpha / \beta$ mixture ( $\delta 100.5 \mathrm{ppm}\left[{ }^{1} J_{\mathrm{C} 1-\mathrm{H} 1}=172 \mathrm{~Hz}\right.$, for the $\alpha$-anomer $]$ ).

Additionally, glycosylation of dibenzyl phosphate using the mixture 18/19 was successful and furnished the expected mixture of tetrazole $N$-regioisomers in $72 \%$ yield. These materials were not separated and instead exposed to hydrogenolysis conditions to deliver free D-manno C6-tetrazole 1-phosphate 21. Deprotection utilised 0.6 equiv of $\mathrm{Pd} / \mathrm{C}(0.1$ equiv per benzyl group) and 0.6 equiv of $\mathrm{Pd}(\mathrm{OH})_{2} / \mathrm{C}$ to afford $\mathbf{2 1}$ in $72 \%$ yield after $24 \mathrm{~h}$. NMR analysis of $\mathbf{2 1}$ confirmed the presence of a C6-tetrazole $\left(\delta_{\mathrm{C}}=160.8 \mathrm{ppm}\right)$, alongside an anomeric phosphate $\left(\delta_{\mathrm{P}}=-2.15 \mathrm{ppm}\right)$, and ${ }^{1} \mathrm{H}$ coupling constant data ( $\delta 5.41 \mathrm{ppm}\left[\mathrm{dd}, J=7.9,1.7 \mathrm{~Hz}, \mathrm{H}_{1}\right]$ ) supported an $\alpha$-linked manno 1-phosphate derivative. This material complimented our recently reported C6-hydroxamic acid derivative as a bioisostere for mannuronic acid 1-phosphate [20], and will be enabling for evaluating non-native glycosyl 1-phosphates in appropriate chemoenzymatic syntheses [21-23].

\section{Conclusion}

We have established synthetic access to a series of C6-tetrazole thioglycoside monosaccharide building blocks with capability for orthogonal $\mathrm{C} 4$ - and tetrazole $\mathrm{N}$-protecting groups. We demonstrate anomeric manipulation of these donors to new, biologically relevant 1-phosphate and conjugable, aminopropyltethered materials as mimics of mannuronic acid. Evaluation of these C6-tetrazole thioglycosides as donors for non-native alginate fragment synthesis is currently underway and will be reported in due course.

\section{Supporting Information}

\section{Supporting Information File 1}

Detailed experimental protocols and characterisation data; spectral NMR data $\left({ }^{1} \mathrm{H},{ }^{13} \mathrm{C},{ }^{31} \mathrm{P}\right.$ and HSQC NMR for compounds $2-5,7-14,16-18,20$ and 21 ).

[https://www.beilstein-journals.org/bjoc/content/ supplementary/1860-5397-17-110-S1.pdf]

\section{Acknowledgements}

We thank the EPSRC UK National Mass Spectrometry Facility (NMSF) at Swansea University.

\section{Funding}

Keele University is acknowledged for a studentship to E. D.

\section{ORCID ${ }^{\circledR}$ iDs}

Gavin J. Miller - https://orcid.org/0000-0001-6533-3306

\section{Preprint}

A non-peer-reviewed version of this article has been previously published as a preprint: https://doi.org/10.3762/bxiv.2021.25.v1

\section{References}

1. Lee, K. Y.; Mooney, D. J. Prog. Polym. Sci. 2012, 37, 106-126. doi:10.1016/j.progpolymsci.2011.06.003

2. Ertesvåg, H. Front. Microbiol. 2015, 6, 523. doi:10.3389/fmicb.2015.00523

3. Sabra, W.; Zeng, A.-P.; Deckwer, W.-D. Appl. Microbiol. Biotechnol. 2001, 56, 315-325. doi:10.1007/s002530100699

4. Jia, J.; Richards, D. J.; Pollard, S.; Tan, Y.; Rodriguez, J.; Visconti, R. P.; Trusk, T. C.; Yost, M. J.; Yao, H.; Markwald, R. R.; Mei, Y. Acta Biomater. 2014, 10, 4323-4331. doi:10.1016/j.actbio.2014.06.034

5. Sun, J.; Tan, H. Materials 2013, 6, 1285-1309. doi:10.3390/ma6041285

6. Zhang, Q.; van Rijssel, E. R.; Walvoort, M. T. C.; Overkleeft, H. S.; van der Marel, G. A.; Codée, J. D. C. Angew. Chem., Int. Ed. 2015, 54, 7670-7673. doi:10.1002/anie.201502581

7. Dinkelaar, J.; van den Bos, L. J.; Hogendorf, W. F. J.; Lodder, G.; Overkleeft, H. S.; Codée, J. D. C.; van der Marel, G. A. Chem. - Eur. J. 2008, 14, 9400-9411. doi:10.1002/chem.200800960

8. van den Bos, L. J.; Dinkelaar, J.; Overkleeft, H. S.; van der Marel, G. A. J. Am. Chem. Soc. 2006, 128, 13066-13067. doi:10.1021/ja064787q

9. Pan, D.; Zhang, L.; Hua, Q.; Yang, Y. Org. Biomol. Chem. 2019, 17, 6174-6177. doi:10.1039/c9ob01254k

10. Codée, J. D. C.; van den Bos, L. J.; de Jong, A.-R.; Dinkelaar, J.; Lodder, G.; Overkleeft, H. S.; van der Marel, G. A. J. Org. Chem. 2009, 74, 38-47. doi:10.1021/j08020192

11. Dimitriou, E.; Miller, G. J. Org. Biomol. Chem. 2019, 17, 9321-9335. doi:10.1039/c9ob02053e

12. Ostrovskii, V. A.; Trifonov, R. E.; Popova, E. A. Russ. Chem. Bull. 2012, 61, 768-780. doi:10.1007/s11172-012-0108-4 
13. Walvoort, M. T. C.; van den Elst, H.; Plante, O. J.; Kröck, L.; Seeberger, P. H.; Overkleeft, H. S.; van der Marel, G. A.; Codée, J. D. C. Angew. Chem., Int. Ed. 2012, 51, 4393-4396. doi:10.1002/anie.201108744

14. Lassalas, P.; Gay, B.; Lasfargeas, C.; James, M. J.; Tran, V.; Vijayendran, K. G.; Brunden, K. R.; Kozlowski, M. C.; Thomas, C. J.; Smith, A. B., III; Huryn, D. M.; Ballatore, C. J. Med. Chem. 2016, 59, 3183-3203. doi:10.1021/acs.jmedchem.5b01963

15. Wittenberger, S. J.; Donner, B. G. J. Org. Chem. 1993, 58, 4139-4141. doi:10.1021/jo00067a058

16. Mende, M.; Nieger, M.; Bräse, S. Chem. - Eur. J. 2017, 23, 12283-12296. doi:10.1002/chem.201701238

17. Mitra, B.; Mukherjee, S.; Pariyar, G. C.; Ghosh, P. Tetrahedron Lett. 2018, 59, 1385-1389. doi:10.1016/j.tetlet.2018.02.067

18. Ostrovskii, V. A.; Koren, A. O. Heterocycles 2000, 53, 1421-1448. doi:10.3987/rev-00-530

19. Ahmadipour, S.; Pergolizzi, G.; Rejzek, M.; Field, R. A.; Miller, G. J. Org. Lett. 2019, 21, 4415-4419. doi:10.1021/acs.orglett.9b00967

20. Beswick, L.; Dimitriou, E.; Ahmadipour, S.; Zafar, A.; Rejzek, M.; Reynisson, J.; Field, R. A.; Miller, G. J. ACS Chem. Biol. 2020, 15, 3086-3092. doi:10.1021/acschembio.0c00426

21. Beswick, L.; Ahmadipour, S.; Dolan, J. P.; Rejzek, M.; Field, R. A.; Miller, G. J. Carbohydr. Res. 2019, 485, 107819. doi:10.1016/j.carres.2019.107819

22. Ahmadipour, S.; Beswick, L.; Miller, G. J. Carbohydr. Res. 2018, 469, 38-47. doi:10.1016/j.carres.2018.09.002

23. Ahmadipour, S.; Miller, G. J. Carbohydr. Res. 2017, 451, 95-109. doi:10.1016/j.carres.2017.08.014

\section{License and Terms}

This is an Open Access article under the terms of the Creative Commons Attribution License (https://creativecommons.org/licenses/by/4.0). Please note that the reuse, redistribution and reproduction in particular requires that the author(s) and source are credited and that individual graphics may be subject to special legal provisions.

The license is subject to the Beilstein Journal of Organic Chemistry terms and conditions:

(https://www.beilstein-journals.org/bjoc/terms)

The definitive version of this article is the electronic one which can be found at:

https://doi.org/10.3762/bjoc.17.110 